\title{
EPISTEMIC CONTRASTIVISM
}

(penultimate version of an entry for the Routledge Encyclopedia of Philosophy, 2017)

Peter Baumann

Contrastivism about knowledge is the view that one does not just know some proposition. It is more adequate to say that one knows something rather than something else: I know that I am looking at a tree rather than a bush but I do not know that I am looking at a tree rather than a cleverly done tree imitation. Knowledge is a three-place relation between a subject, a proposition and a contrast set of propositions. There are several advantages of a contrastivist view but also certain problems with it.

1. Contrastivism

2. Pro Contrastivism

3. Contra Contrastivism

1. Contrastivism

According to an orthodox view, knowledge is a binary relation between a subject and a proposition. Contrastivism about knowledge (or "contrastivism") is the view that 
knowledge is rather a ternary relation between a subject, a (true) target proposition and a (false) contrast proposition (or a set of contrast propositions) which is incompatible (but cf. Rourke 2013, sec.2) with the target proposition. The form of a knowledge-attributing sentence is "S knows that $p$, rather than $q$ " rather than "S knows that $p$ " (see Sinnott-Armstrong 2004 and 2008, Schaffer 2004a, 2005, 2007a, 2007b, 2008, Karjalainen and Morton 2003, Morton 2013; see also Morton 2011 and Schaffer 2012a). To say, for instance, that Jean knows that there is a dog in front of her, is elliptical and short for the claim that Jean knows that there is a dog in front of her rather than, say, a cat. This is compatible with Jean not knowing that there is a dog in front of her rather than a wolf.

Contrastivism shares certain similiarities with relevant alternative views according to which knowledge does not require that the subject can rule out all alternative possibilities but only the "relevant" ones. Relevant alternatives views, however, typically stick with a binary analysis of knowledge (see, e.g., Dretske 1970). Some contrastivists embrace contextualism, - the view that the meaning of a knowledge sentence varies with the context of the speaker; they claim that the set of contrast propositions is determined by the speaker's context (see, e.g., Schaffer 2005; for a non-contextualist contrastivism see Sinnott-Armstrong 2002, 2004).

Before epistemologists developed contrastivist accounts of knowledge (and other epistemic relations) philosophers of science proposed contrastivist accounts of explanation or causation (see, e.g., Hitchcock and Schaffer in Blaauw 2013b). Recently, some authors have developed contrastivist accounts of practical reasons 
and of related notions (see Snedegar 2013 and Sinnott-Armstrong 1996, 2006; see also Sinnott-Armstrong, Driver and Snedegar in Blaauw 2013b). There are also contrastivist views about justification or confirmation (see Fitelson in Blaauw 2013b and Sinnott-Armstrong 2002, 2004, 2006, ch.5) or about belief (see Blaauw 2013a and Baumann 2008, appendix).

\section{Pro Contrastivism}

Contrastivists take some encouragement for their views from data about ordinary usage of terms like "knowledge" (see, e.g., Schaffer 2008 or 2005, sec.3). However, recent experimental data have not led to much agreement here (see Schaffer and Knobe 2012 but also Pinillos 2011, DeRose 2011, Gerken and Beebe 2016).

Other kinds of arguments seem to carry more weight. Jonathan Schaffer has presented a couple of linguistic arguments (see Schaffer 2004a, 77-79, 2005, sec.3). First, even though knowledge ascriptions often have an explicitly binary form there is reason to assume that there is a hidden variable for contrasts because there are also explicitly ternary forms of knowledge ascriptions. Second, there are phenomena of binding by quantifiers which suggest a hidden variable for contrasts ("On every test, Jones knows that the substance is A" is analyzed along the lines of "For every test and for every alternative substance in the test, Jones knows that the tested substance is A rather than the alternative"). Third, contrast preservation under ellipsis also suggests a hidden contrast variable: If, e.g., Holmes knows that Mary stole the bicycle rather 
than the wagon, then "Holmes knows that Mary stole the bike, and Watson does too" preserves the contrast in the case of Watson. Fourth, focus differences suggest hidden variables for contrasts: "Mary STOLE the bike" suggests a contrast with borrowing etc. while "Mary stole the BIKE" suggests a contrast with wagon etc. Fifth, the assumption of hidden contrast variables can explain surface paradoxes (see also Schaffer 2004a, 81). Suppose that Jill can distinguish between dogs and cats but not between dogs and wolfs. Facing a dog, one wants to say both that she knows that there is a dog (rather than a cat) and that she does not know that there is a dog (rather than a wolf). For a detailed critique of all these arguments by Schaffer see Rickless 2014.

A further, semantic argument concerns the relation between knowledge and questions (see Schaffer 2005, sec.1-3, 2007a, 2007b and Sawyer 2014, sec.2): Knowing some proposition is knowing the (correct) answer to a (contextually salient) particular question. Since "all well-formed questions are multiple-choice questions" (Schaffer 2007a, 240), the known answer to a question is contrastive in nature, and thus also the knowledge of the corresponding proposition. One might wonder whether "knowing is knowing the answer" (Schaffer 2007b, 383). Even if knowing only requires knowing the answer (still a controversial claim) it is not obvious that knowledge inherits contrastivity from the latter or from the contrastive nature of the question. Apart from that, not everyone does agree that all questions are multiplechoice questions. 
Adam Morton has argued that since tracking of objects is contrastive (I can see that you went into the kitchen rather than the bathroom but I cannot see which part of the kitchen), the corresponding knowledge is contrastive, too (see Morton 2013, sec.1-2). Similarly, since evidence is contrastive (I have evidence that I am talking to Chuck rather than Jill but not that I am talking to Chuck rather than his twin brother), the corresponding knowledge is contrastive, too (see Morton 2013, sec.3). However, since characteristics of a necessary condition of some $\mathrm{X}$ need not be characteristics of $\mathrm{X}$, too, it would be interesting to see more detailed arguments here (see also Sawyer 2014, sec.2 here with respect to perceptual knowledge).

Contrastivism also offers solutions to major epistemological problems like the following skeptical puzzle (containing plausible premises and an implausible conclusion): Jay does not know that he has not been deceived by some Cartesian demon into falsely believing that he has hands; if he does not know the latter, then he does not know that he has hands; hence, Jay does not know that he has hands (see, for many, DeRose 1995, 1). This easily generalizes with respect to subjects, propositions and sceptical scenarios. The conditional premise is usually supported by some principle of epistemic closure under known entailment (schematically and roughly: If $\mathrm{S}$ knows that $p$, and if $\mathrm{S}$ also knows that $p$ entails $q$, then $\mathrm{S}$ knows that $q$ ). Given knowledge of the relevant conditional (If I have hands, then I have not been deceived by some Cartesian demon into falsely believing that I have hands), the second, conditional premise of the skeptical argument follows. 
The contrastivist has an elegant solution for this skeptical paradox (see Schaffer $2004,80,2004 \mathrm{~b}, 2005$, sec.5). If one makes the relevant contrasts explicit, then the premises and the alleged conclusion have to be reformulated. It turns out then that Jay does not know that he has hands rather than being deceived by some Cartesian demon into falsely believing that he has hands; however, it also turns out that Jay knows that he has hands rather than, say, stumps. No sceptical argument goes through and the paradox is resolved. By limiting the scope of both common sense and scepticism, the contrastivist can make the two views compatible with each other: Subjects do know ordinary propositions like I have hands but cannot know that they are not in a sceptical scenario. The contrastivist can do this while holding on to a principle of closure (for a contrastivist closure principle see especially Schaffer 2007a).

The contrastivist response to scepticism is in some ways very similar to contextualist responses and is as controversial as the latter (see the exchange between Luper 2012 and Blaauw 2012). Does common sense not contain stronger claims ("I just know that I have hands, period!") than the weaker contrastive ones ("Sure, I know that I have hands rather than wings!")? And is not the point of scepticism its damaging effect on ordinary knowledge claims rather than just the denial that one can know that one is not in some extravagant sceptical scenario?

Finally, it has been argued that contrastivism can capture and describe the stage and progress of inquiry: It can explain in detail what is known and what is not (yet) known - which (multiple-choice) questions can be answered at a certain stage and 
which not (see Schaffer 2004a, 81, 2005, 237). Contrastivism thus describes the epistemic abilities and accomplishments of subjects in more detail than binary accounts.

\section{Contra Contrastivism}

There are alternatives to contrastivist explanations of the way people talk about knowledge. Some people argue that the relevant contrasts concern knowledge's content, correctly characterizable as adjunctive (" $p$ rather than $q$ "; see Blaauw 2008, sec.2), as conjunctive (" $p$ and not $q$ "; see Jespersen 2008 and also Kallestrup 2009, sec.1), or as conditional ("if $p$ or $q$, then $p$ "; see van Woudenberg 2008, 283, passim; see against this kind of strategy Schaffer 2008).

A more serious threat to contrastivism is, perhaps, the objection that the contrastivist leaves something important out when they ascribe knowledge that $p$, rather than $q$ : The subject might typically work with the assumption that either $p$ or $q$ is true (see Becker 2009, 253-254). If the corresponding (multiple-choice) question (" $p$ or $q$ ?") provides information and testimonial knowledge to the subject that one of the two is true (see Montminy 2008, 130-131), then there is still a good case for a binary knowledge attribution (the subject knows that $p$ by disjunctive syllogism). Schaffer has replied that the subject need not be aware of the question and also does not need to trust the would-be informants (see Schaffer 2005, 250, fn.20; see also Steglich-Petersen 2015 on the role of presuppositions). 
A further objection says that contrastivism makes knowledge "too easy" in many cases. Somebody who has next to no clue about Mongolia could still know that Ulan Bator rather than Vatican City is the capital of Mongolia (see Montminy 2008, 130132). Intuitions diverge on this: Some (see, e.g., Schaffer 2005, 257) hold that this is not so implausible. As long as one does not deny the difficulty of knowing some things, it might be fine to accept the easiness of knowing some other things.

A related objection (see Becker 2009, 255-256) says that the contrastivist analysis is vulnerable to a problem of "lucky questions". For instance, someone who finds themselves unwittingly in fake barn county but happens to look at one of the few veritable barns might thus count as knowing that there is a barn rather than a farmhouse in front of them. However, the belief that there is a barn is true only by luck and thus cannot qualify as knowledge. This constitutes another way in which knowledge might come "too easily", given contrastivism. The contrastivist could reply that while the subject does not know that there is a barn rather than a fake barn in front of them, they still know that it is a barn rather than a farmhouse. Apart from that, the contrastivist could embrace the view that knowledge is compatible with this kind of luck. A contrastivist account of belief might offer additional resources to escape this objection: The belief that that's a barn rather than a farmhouse might not qualify as lucky.

Even if contrastivism is somewhat plausible one might wonder whether all knowledge is contrastive. What for instance is the contrast proposition for knowledge that $2+2=4 ? 2+2=4$ rather than what? There does not seem to be a plausible answer 
to this question. Similar things can be said about basic logical knowledge (I know that everything is self-identical rather than what?) or semantic knowledge (I know that vixen are female foxes rather than what?). It does not help to say that in such cases the contrast proposition is simply the negation of the target proposition; this would trivialize contrastivism and make it collapse into a binary view (see Morton and Karjalainen 2008, 272 but also cf. Buenting 2010). So, contrastivism might only have some plausibility for certain kinds of knowledge, like knowledge based on discriminatory cognitive abilities (e.g., perceptual ones), but not for others (see Becker 2007, 83, Baumann 2008, sec.1, and Luper 2012, 56; on the role of discrimination here see Schaffer 2004b, Morton and Karjalainen 2008, and Sawyer 2014, sec.2).

Finally (echoing certain objections against contextualism), one could point out that normally subjects are blind to the contrastivity of knowledge attributions. Does the contrastivist then have to offer a convincing error theory which explains the systematicity of the mistake? It might be an open empirical question whether people are or are not aware of contrastive effects. Apart from that, one might also simply accept and even defend the claim of semantic blindness (see Schaffer and Szabó 2014, 533-535).

But, one might follow up, how is thought and communication about knowledge possible when speakers and hearers are blind to the existence of a third relatum? Are they then even talking or thinking about it at all (in the full sense)? On the other hand, how is thought about knowledge possible when they are not blind to the contrasts: 
Would not normal subjects be overloaded by the additional complexity? And how then is communication possible if (as perhaps usual) the contrasts the speaker has in mind are not made explicit to the hearer (and vc. vs.)? Can one simply rely on the idea that normally speakers and hearers share the same context and thus the same set of contrast propositions? At least some of these open questions can only be answered on an empirical basis.

See also: ConteXTUALISM, EPISTEMOLOGICAL; EPISTEMIC RELATIVISM; KNOWLEDGE, CONCEPT OF; RELEVAnT AlternativeS; SCEPTICISM; SubJECT-SENSITIVE InVARIANTISM

\section{References and further reading}

Baumann, P. (2008) 'Contrastivism Rather than Something Else? On the Limits of Epistemic Contrastivism', Erkenntnis 69: 189-200.

(Critique of contrastivism, including the claim that contrastivism does not apply to all kinds of knowledge; includes an appendix on contrastivism about belief)

(2012) 'PS: Response to Schaffer's Reply', S. Tolksdorf (ed.), Conceptions of Knowledge, Berlin: de Gruyter, 425-431.

(Response to a reply by Schaffer to the author's criticism)

Becker, K. (2007) Epistemology Modalized, New York \& London: Routledge. 
(Important monograph on modal epistemology and reliabilism; includes a brief passage on contrastivism (80-86))

- (2009) 'Contrastivism and Lucky Questions', Philosophia 37: 245-260.

(Presents the Lucky Questions objection)

Blaauw, M. (2008) 'Contra Contrastivism', Philosophical Issues 18: 2-34.

(Criticizes Schaffer's rejection of the adjunction strategy in Schaffer 2008)

----- (2012) 'Defending Contrastivism', International Journal for the Study of Skepticism 2: 59-64.

(Replies to Luper's critique of contrastivist responses to scepticism)

----- (2013a) 'Contrastive Belief', M. Blaauw (ed.), Contrastivism in Philosophy, New York: Routledge, 88-100.

(Perhaps the most detailed attempt to apply contrastivism to beliefs)

----- (ed.) (2013b) Contrastivism in Philosophy, New York: Routledge.

(Representative anthology on contrastivism in different areas of philosophy)

Buenting, J. (2010) 'An Epistemic Reduction of Contrastive Knowledge Claims', Social Epistemology 24: 99-104.

(Proposes to analyze the contrast proposition as the negation of the target proposition and argues that a binary account results from this)

DeRose, K. (1995) 'Solving the Skeptical Problem', Philosophical Review 104: 1-52. (Important discussion of recent Cartesian skepticism; develops a contextualist response) (2011) 'Contextualism, Contrastivism, and X-Phi Surveys', Philosophical Studies 156: 81-110. 
(Discussion of experimental work relating to contrastivism and contextualism; also comments on Schaffer and Knobe 2012)

Dretske, F. (1970) 'Epistemic Operators', Journal of Philosophy 67: 1007-1022.

(Classic paper on closure as well as on relevant alternatives)

----- (1972) 'Contrastive Statements', Philosophical Review 81: 411-437.

(On contrasts; in many ways a precursor of some aspects of contrastivism)

Gerken, M. and Beebe, J.R. (2016) 'Knowledge in and out of Contrast', Noûs 50: 133164.

(Critical discussion of experimental work relating to contrastivism)

Hughes, M. (2013) 'Problems for Contrastive Closure: Resolved and Regained', Philosophical Studies 163: 577-590.

(Defends principles of contrastivist closure)

Jespersen, B. (2008) 'Knowing that $p$ rather than $q$ ', Sorites 20: 125-134.

(Discusses the conjunctive analysis of contrastive knowledge attributions)

Johnson, B.C. (2001) 'Contextualist Swords, Skeptical Plowshares', Philosophy and Phenomenological Research 62: 385-406.

(Contains some remarks on the contrastivist nature of relevant alternative accounts of knowledge)

Kallestrup, J. (2009) 'Knowledge-wh and the Problem of Convergent Knowledge', Philosophy and Phenomenological Research 78: 468-476.

(Discusses interrogative knowledge-wh ascriptions and the problem of "convergent knowledge"; also discusses conjunctive strategies of analyzing contrastive knowledge attributions) 
Karjalainen, A. and Morton, A. (2003) 'Contrastive Knowledge', Philosophical Explorations 6(2): 74-89.

(Early proposal of contrastivism by two of its major defenders)

Kelp, C. (2011) 'A Problem for Contrastivist Accounts of Knowledge', Philosophical Studies 152: 287-292.

(Criticizes Schaffer's contrastivist closure principle)

Kvanvig, J. (2007) 'Contexualism, Contrastivism, Relevant Alternatives', and Closure, Philosophical Studies 134: 131-140.

(Contains a discussion of contrastivist closure)

Luper, S. (2012) 'Contrastivism and Skepticism', International Journal for the Study of Skepticism 2: 51-58.

(Critique of contrastivist repsonses to scepticism)

Montminy, M. (2008) 'Cheap Knowledge and Easy Questions', Grazer Philosophische Studien 77: 127-146.

(Critique of contrastivism; includes the objection that it makes knowledge "too easy")

Morton, A. (2011) 'Contrastivism', S. Bernecker and D. Pritchard (eds.), The Routledge Companion to Epistemology, London etc.: Routledge, 513-522.

(Exposition and defense of contrastivism)

----- (2013) 'Contrastive Knowledge', M. Blaauw (ed.), Contrastivism in Philosophy, New York: Routledge, 101-115.

(Exposition and defense of contrastivism; includes a discussion of the contrastivity of tracking and of evidence) 
Morton, A. and Karjalainen, A. (2008) 'Contrastivity and Indistinguishability', Social Epistemology 22: 271-280.

(Discussion of different kinds of contrastive expressions and of closure; defense of a restricted contrastivism about beliefs on pp.278-279)

Pinillos, N.Á. (2011) 'Some Recent Work in Experimental Epistemology', Philosophy Compass 6: 675-688.

(On relevant experimental work; also on Schaffer and Knobe 2012)

Rickless, S.C. (2014) 'The Contrast-Insensitivity of Knowledge Ascriptions', Philosophy and Phenomenological Research 88: 533-555.

(Detailed critique of Schaffer's linguistic arguments for contrastivism)

Sawyer, S. (2014) 'Contrastive Self-Knowledge', Social Epistemology 28: 139-152.

(Defends contrastivism about self-knowledge and about perceptual knowledge; argues for contrastivism about belief in sec.3)

Schaffer, J. (2004a) 'From Contextualism to Contrastivism', Philosophical Studies 119: 73-103.

(An early defense of contrastivism by one of the most important contrastivists; contains linguistic arguments for contrastivism)

----- (2004b) 'Skepticism, Contextualism, and Discrimination', Philosophy and Phenomenological Research 69: 138-155.

(Discusses contrastivism with respect to scepticism as well as discriminatory abilities) (2005) 'Contrastive Knowledge', T.S. Gendler and J. Hawthorne (eds.), Oxford Studies in Epistemology, vol.1, 235-271. 
(Exposition and defense of contrastivism; contains a discussion of question-relativity as well as scepticism and closure; discusses contrastivism about belief in sec.4)

- (2007a) 'Closure, Contrast, and Answer', Philosophical Studies 133: 233-255.

(The most detailed proposal of a principle of contrastivist closure)

----- (2007b) 'Knowing the Answer', Philosophy and Phenomenological Research 75: 383-403.

(On interrogative knowledge-wh ascriptions and the problem of "convergent knowledge; defends the claim of the question-relativity of knowledge)

(2008) 'The Contrast-Sensitivity of Knowledge Ascriptions', Social Epistemology 22: $235-245$.

(Defends contrastivism and criticizes the conjunction, conditional and adjunction strategy)

----- (2012a) 'What Is Contrastivism?', S. Tolksdorf (ed.), Conceptions of Knowledge, Berlin: de Gruyter, 353-356.

(Brief exposition and defense of contrastivism)

----- (2012b) 'Contrastive Knowledge: Reply to Baumann', S. Tolksdorf (ed.), Conceptions of Knowledge, Berlin: de Gruyter, 411-424.

(Reply to Baumann's critique of contrastivism)

Schaffer, J. and Knobe, J. (2012) 'Contrastivism Surveyed’, Noûs 46: 675-708.

(Discusses contrastivism and its alternatives with respect to experimental data)

Schaffer, J. and Szabó, Z.G. (2014) 'Epistemic Comparativism: A Contextualist Semantics for Knowledge Ascriptions', Philosophical Studies 168: 491-543. (Proposes a semantics of knowledge attributions) 
Sinnott-Armstrong, W. (1996) 'Moral Skepticism and Justification', W. SinnottArmstrong and M. Timmons (eds.), Moral Knowledge? New Readings in Moral Epistemology, Oxford: Oxford University Press, 3-48.

(One of the earliest defenses of contrastivism, especially moral contrastivism, by one of the most important contrastivists)

------ (2002) 'What's in a Contrast Class?', Analysis 62: 75-84.

(One of the first expositions and defenses of contrastivism about justification)

------ (2004) 'Classy Pyrrhonism', W. Sinnott-Arnstrong (ed.), Pyrrhonian Skepticism, Oxford: Oxford University Press, 188-207.

(Defends contrastivism about justification while accepting scepticism about the relevant contrast class)

------ (2006) Moral Skepticisms, Oxford: Oxford University Press.

(Important monograph on moral epistemology defending moral contrastivism and contrastivism about justification in detail; accepts scepticism about the relevant contrast class)

----- (2008) 'A Contrastivist Manifesto', Social Epistemology 22: 257-270.

(Defends the author's own version of epistemic contrastivism)

Snedegar, J. (2013) 'Reason Claims and Contrastivism about Reasons', Philosophical Studies 166: 231-242.

(Defends contrastivism about practical reasons)

Steglich-Petersen, A. (2015) 'Knowing the Answer to a Loaded Question', Theoria 81: 97-125.

(Criticizes Schaffer for neglecting the role of presuppositions in knowledge attributions) 
Swinburne, R. (2001) Epistemic Justification, Oxford: Clarendon.

(Mainly on epistemic justification but contains a brief remark (34) suggesting contrastivism)

van Woudenberg, R. (2008) 'The Knowledge Relation: Binary or Ternary?', Social Epistemology 22: 281-288.

(Argues for a binary account and for the conditional strategy)

PETER BAUMANN 